\title{
PROIDETEICA
}

\section{¿SERVILISMO O AUTONOMÍA? EL PROYECTO DE AUTONOMÍA FRENTE A LA NUEVA HETERONOMÍA}

\author{
Servility or Autonomy? The Autonomy Project \\ against the New Heteronomy
}

Emanuele Profumi ${ }^{50}$

(EHESS-CESPRA, Francia)

\begin{abstract}
Resumen
La crítica de la descomposición de la sociedad que sostiene Castoriadis, y más precisamente la idea de un declive de la autorrepresentación de la sociedad, o de su dimensión social-histórica, es decir, su consistencia ontológica, debe ser revisada. La insignificancia de la sociedad contemporánea no puede jugar un rol central dentro del análisis crítico si pensamos que esta sociedad es también la expresión de una nueva heteronomía. Con las mismas categorías filosóficas de Castoriadis debemos rechazar la idea de descomposición y elaborar una crítica del presente. Para pensar la actualidad del "proyecto de autonomía", el particular, es necesario sobre todo concentrarse en la naturaleza de esta nueva forma de dominación. Este trabajo crítico es urgente, si consideramos la actual bifurcación social-histórica de las sociedades occidentales: es necesario comprender la oposición entre democracia y capitalismo a través de la alternativa entre la servil y activa defensa del statu quo y una praxis de autonomía, base de esta bifurcación.
\end{abstract}

Palabras clave: Castoriadis | Crítica filosófica | Insignificancia | Heteronomía | Proyecto de autonomía.

\begin{abstract}
Cornelius Castoriadis' analysis of contemporary society is partially correct. For understanding our social-historical existence, we have to develop his idea of "general conformism", and to link it with his critical reconstruction of the capitalist society. At the same time, we need to reject his most important thesis on the "social insignificance": the idea of a supposed auto-
\end{abstract}

50. Traducción del francés de Emiliano Aldegani. 


\title{
PROIPIETEICA
}

dissolution of the central imaginary of the contemporary society is not correct from a logical and historical point of view. We are living in a society characterized from a new tenuous heteronomy, not in a dissolution of the society in itself. Moreover, the castoriadian "project of autonomy" is not still disappeared, as the greek-french philosopher feared. Thanks to the "no global" and the "indignados" movements, there is a new expression of this project. For its survival, we have to understand and to overcome the new voluntary servitude which is deeply connected with the present capitalist social organisation of values and significations. The actual "crisis" situation could be a chance to continue this project and to take part of the process which is opposing capitalism to democracy. The future of this project is linked with our possibilities to make free institutions and to change our ways of socializing.

Keywords: Castoriadis | Philosophical Critique | Insignificance | Heteronomy | Autonomy Project.

\section{La descomposición de la sociedad para Castoriadis}

\begin{abstract}
En derrumbe de la autorrepresentación de la sociedad, el hecho de que éstas sociedades ya no puedan presentarse como esto (de un modo que no sea meramente exterior y descriptivo)- no sin que ese esto como lo que se presenta se derrumbe, se aplaste, se vacíe, se contradiga. Ésta es una manera de decir que hay crisis de las significaciones imaginarias sociales, y que éstas no proveen a los individuos las normas, los valores, las referencias y motivaciones que le permiten, a la vez, hacer funcionar la sociedad, y seguir siendo ellos mismos, más o menos bien, en un equilibrio viable. [...]. [...] Ahora bien, esto que precisamente está en crisis hoy, es la sociedad como tal para el hombre contemporáneo. (Castoriadis: 1996. 29-30)
\end{abstract}

Castoriadis piensa que el carácter social e histórico al fondo del ser mismo de la sociedad (lo Social-histórico), así como las significaciones centrales en torno de las que se organiza una sociedad cualquiera, no están ya a la altura de organizar la sociedad actual. Por esta razón, el problema más importante que debemos resolver, el que marca todos los aspectos de la vida, es que estamos en un período de descomposición de la sociedad, en una crisis social-histórica. Ésta es la tesis filosófico-política principal de Castoriadis sobre la segunda mitad del siglo pasado.

Él radicaliza su tesis de los años 60’ sobre la privatización de las sociedades modernas, para afirmar que la "Crisis" no es simplemente una contradicción de 


\section{PROIFIETEICA}

la sociedad capitalista, sino el hecho de que esta sociedad está produciendo la auto-destrucción de la sociedad como tal.

Con el nacimiento de su filosofía de la creación, es decir con el desarrollo de su propia y original posición filosófico-política, las tesis social-bárbaras ${ }^{51}$ del período entre 1950 y 1960 sobre la burocratización y sobre la privatización de la vida social y política, al igual que las tesis sobre la disolución del sentido del trabajo efectuada por la lógica del capitalismo y por las instituciones, se transforman. Entre los años 1970 y 1980, devienen dos tesis firmemente sostenidas, en particular a partir de 1990:

1. Las instituciones de la están atravesadas por el ascenso de la insignificancia (Castoriadis, 1996: 11-26/83-102).

2. Estamos en presencia de una época de conformismo generalizado. (Castoriadis, 1990: 11-28).

Éstos son los dos fenómenos que marcan la descomposición de la sociedad y que son, para Castoriadis, las dos caras de la misma moneda. La naturaleza ontológica de la nueva sociedad es su descomposición interna.

Pero, en verdad, solamente la primera tesis es coherente con la idea de descomposición (Castoriadis, 2013: 122-131), mientras que la segunda nos obliga a revisar la crítica castoridiana de la sociedad contemporánea y, en particular, el fenómeno de la insignificancia que, para Castoriadis, la marca en profundidad.

Para percibir este problema en el marco de la reflexión del filósofo grecofrancés, es necesario reconstruir brevemente la lógica que subyace a estas dos tesis que sostienen la idea de la descomposición.

\section{Insignificancia}

Según nuestro filósofo, con excepción de un breve período en 1968 y en el curso de los movimientos sociales contemporáneos, principalmente del movimiento ecologista y del movimiento feminista, estamos en presencia de una gran

51. Alusión a la revista Socialisme ou Barbarie, de la cual Castoriadis fue miembro fundador junto a Claude Lefort, y en la que publicó numerosos artículos desde fines de la década del 40 hasta 1967. [Nota del traductor] 


\section{PROIFIETEICA}

transformación social, inédita, en la que las sociedades occidentales no están más en condiciones de proponer su propia creación global y de afirmar una nueva creación histórico-social, enfrentándose con las angustias de un fenómeno regresivo, a saber, la disolución de la significación (del valor de las significaciones imaginarias sociales y de las instituciones en las que se encarnan).

Esto ocurre no sólo a nivel político, sino también a nivel social y cultural. La descomposición política está marcada por la despolitización, la privatización, la apatía, la atrofia de la imaginación política, y, sobre todo, por la evanescencia del conflicto social y político. La desagregación social es una pérdida de puntos de referencia y del sentido de la identidad de la colectividad (todo lo que nos permite percibir el mundo y otorgarle un sentido), se manifiesta por la confusión y la disolución de las identidades sociales: ya no investimos sobre todo en la educación y en la escuela, los roles familiares son en adelante ignorados, y las identidades sexuales confundidas. La decadencia cultural se caracteriza por un desvanecimiento profundo del espíritu crítico auténtico, que es desprovisto de vigor cuando es expresado al interior del dominio de la lógica publicitaria y de la posmodernidad intelectual y artística, y en consecuencia, se propaga la anomia y la desorientación informa, dota a la perdida de sentido, a su vuelta por el desgaste de las significaciones y por la pérdida de valores. Todo esto conduce a una inseguridad psíquica generalizada. A su vez, en el dominio del arte y de la ciencia, como en todos los dominios de la vida, debemos registrar una falta de nuevas creaciones colectivas y de creatividad individual. En resumen, la ausencia de creación colectiva se debe al hecho de que no podemos apreciar más nada, y que nuestros propios valores de referencia dentro de la sociedad se han pulverizado (Castoriadis, 1996: 125-139 / Castoriadis, 2011: 186)

En general, la sociedad contemporánea es incapaz de pensarse en tanto que sociedad, ha perdido su capacidad de auto-representarse ella misma y, por consecuencia, también la de aspirar a ser alguna cosa diferente. Esto se debe al hecho de que los dos componentes de la naturaleza social-histórica de la institución imaginaria se han disipado: la sociedad es padecida y vivida por los 


\section{PROIFIETEICA}

individuos como una dimensión del sufrimiento, mientras que el olvido de la temporalidad, y del pasado, como memoria, y del futuro, como proyecto social, es en adelante la marca de la época. El suicidio de la dimensión social histórica es, probablemente, la razón subyacente que conduce a Castoriadis a hablar de desvanecimiento del proyecto de autonomía acompañado por la difusión de valores incompatibles con una posible sociedad autónoma (Castoriadis, 1996: 22-23).

\section{Conformismo}

El segundo fenómeno central para la sociedad contemporánea, el conformismo, es expresado no sólo en razón de la insignificancia y de la disolución de la creación social-histórica heredada de la época precedente, sino sobre todo por el prevalecimiento de la lógica, del poder $\mathrm{y}$ de las organizaciones de tipo capitalista.

El imaginario capitalista se convierte prácticamente en el horizonte dentro del que Occidente vive y se reproduce. Y ello conduce igualmente hacia el desvanecimiento del proyecto de emancipación humana, porque el capitalismo no tiene necesidad de autonomía sino de conformismo, y a lo largo de décadas ha logrado también tragarse al polo subversivo que lo atacaba. El imaginario capitalista impone la centralidad de la economía en el marco de la vida pública, porque ella deviene la instancia más importante de la organización social: la expansión indefinida del consumo y de la producción que pone en el centro al dinero y al beneficio como valores absolutos. Si en la época de Socialisme ou Barbarie Castoriadis interpreta este fenómeno como una destrucción del sentido que esto provoca en el trabajo, a fines de la década del 70 ésta realidad está a la altura de demencia colectiva, del cinismo, de la corrupción estructural, del culto a lo efímero y de las distracciones de las masas. Si, pese a todo esto, el sistema continúa funcionando, según nuestro filósofo es porque las instituciones capitalistas y liberales son capaces de adaptarse a cualquier situación y ya que pueden sacar provecho de la participación, casi total, de la población en el sistema dominante (Castoriadis, 2011: 251-61). 


\section{PROIFIETEICA}

En resumen, para Castoriadis somos confrontados por una nueva forma de heteronomía débil, que se afirma en las cenizas de una época pasada, de donde era imposible hacerla salir, en razón del movimiento social-histórico todavía apuntado hacia la realización del proyecto de autonomía.

\section{2. ¿Descomposición de la sociedad? No en verdad}

Dentro de este análisis hay dos afirmaciones ontológicas que no pueden ir juntas.

En efecto, por un lado el crecimiento de la insignificancia es coherente con la idea de una descomposición de lo social-histórico, sin embargo, la afirmación de la vitoria del sistema capitalista, la propagación de un conformismo generalizado, y la idea de que un nuevo tipo antropológico que marca a esta sociedad ha nacido, indican más bien que estamos en presencia de una nueva creación de la sociedad en su conjunto, no solamente una nueva forma de dominación sino una nueva organización de la sociedad. Hay algo que se impone como estructural. A fin de cuentas, es el mismo Castoriadis quien cree haber afirmado, no un aspecto accesorio o temporario, sino algo que está en el corazón de la sociedad contemporánea. Tenemos por lo tanto, dos tesis opuestas: por un lado, la sociedad en su conjunto se descompone, y por el otro, ella se impone como una nueva creación general.

A nivel lógico la idea de descomposición se refiere a cualquier cosa que está muriendo, un suicidio de la sociedad como tal, a algo que va a desaparecer luego de un período más o menos largo y no puede ser comprendido como una nueva clase social-histórica capaz de reorganizarse. Descomposición y creación de la sociedad no se pueden dar simultáneamente a nivel ontológico: o tenemos una disolución del ser mismo de la sociedad, o tenemos su nueva afirmación.

¿Por qué Castoriadis habla del nacimiento de un nuevo tipo antropológico, que es más bien la expresión de la afirmación de una nueva sociedad? ¿Por qué sostener que no puede haber una sociedad sin valores, orientaciones, significaciones compartidas, y que el individuo debe identificarse en la institución de la sociedad y en las significaciones que son incorporadas dentro 


\section{PROIFIETEICA}

de cualquier tipo de sociedad?¿Por qué decir, como Castoriadis ha dicho en repetidas ocasiones, que el mundo, como falta sentido, no es más que una ilusión?

Para explicar la paradoja de una sociedad incapaz de ser sociedad, siguiendo al mismo Castoriadis en el corazón de su teoría de la auto-organización general, que quiere que la colectividad se realice por la creación de un núcleo de significaciones y de instituciones centrales alrededor de las que se mueve el imaginario específico de la sociedad en cuestión, podríamos concluir que la sociedad capitalista actual reposa sobre un vacío que constituye este centro.

Pero esto nunca es afirmado por Castoriadis. Al contrario, desde su perspectiva las imágenes de la insignificancia y de la descomposición se refieren más bien a una sociedad que se organiza contra ella misma. Es paradojal, pero para nuestro filósofo la sociedad actual todavía se organiza en torno a un imaginario específico y, al mismo tiempo, ella se está descomponiendo: se acompaña de una nueva heteronomía pero es simplemente incapaz de ser sociedad.

Él se refiere, en efecto y en repetidas ocasiones, a la afirmación de una nueva dominación social o del capitalismo en tanto que proyecto totalitario. Es también por ello que él dice explícitamente del totalitarismo: si queremos buscar un antecedente efectivo de su proyecto de dominación total, lo encontraremos en el imaginario capitalista del dominio ilimitado materializado en la organización de la fábrica (Castoriadis, 2013: 117) Pero, ¿cómo conciliar la constitución de una forma de heteronomía fuerte, como la del totalitarismo, con la realidad de una disolución de la sociedad?

¿Cómo puede hablar de un nuevo tipo antropológico, representado por el gerente burocrático o el especulador, cínico, frustrado y sin escrúpulos, que debe ser el producto de una nueva forma de organización de la sociedad, como todos los tipos antropológicos, y luego afirmar que éste nuevo tipo no está en condiciones de reproducir la sociedad como tal?

Para nuestro filósofo, la creación de una nueva institución de la sociedad es la expresión de un cambio antropológico (psicosocial/socioeconómico) (Castoriadis, 1999: 136). Y agrega que en el caso de la sociedad contemporánea, 


\section{PROIFIETEICA}

vivimos en torno a dos normas centrales: la norma jerárquico-burocrática y la norma del dinero (Castoriadis, 1999: 154). Pero, para él, en última instancia, vivimos dentro de una nueva institución que se caracteriza como la descomposición del ser mismo de la sociedad.

Esta clara paradoja inexplicable es inadmisible a nivel lógico e histórico. Ante la potencia del sistema capitalista financiero, de la globalización neoliberal y del ataque constante que produce contra lo que queda de las instituciones y del imaginario democrático de la época precedente, la tesis de una descomposición de la sociedad como tal, nos parece una herramienta polémica antes que la afirmación de una verdad social-histórica.

Sin embargo, nosotros podemos conservar todavía una parte del análisis de Castoriadis sobre la sociedad contemporánea. Por lo tanto, aceptar la tesis del conformismo generalizado y rechazar la del avance de la insignificancia a la base de la idea de descomposición social nos permite comprender todavía mejor la naturaleza de la nueva forma de heteronomía de la que él mismo habla.

\section{La creación de una nueva sociedad heterónoma}

Pese a que ya no podemos aceptar más que la insignificancia y la descomposición se refieren, por lo tanto, a la sociedad como tal, tenemos todavía en derecho de preguntar: ¿es que, para Castoriadis, gracias también a la disolución de la capacidad de dar sentido, hay algo dentro de la sociedad contemporánea que está muriendo realmente?

Como he mencionado esto que parece morir realmente para Castoriadis es el componente que constituye el proyecto de autonomía con su presupuesto de la valorización de lo Social-histórico que siempre lo ha nutrido. En otros términos, la descomposición social es ante todo un suicidio de esto que deberíamos heredar del proyecto de autonomía, no de la sociedad en tanto tal. Pero este suicidio está en devenir, porque Castoriadis no osa él mismo decir que el proyecto de autonomía este verdaderamente muerto.

A este suicidio todavía en acto del proyecto de autonomía, sería necesario agregar algo que el filósofo greco-francés subestima: él no advierte que su 


\section{PROIFIETEICA}

análisis crítico nos permite leer sutilmente que estamos en presencia también de una nueva forma de servidumbre voluntaria. Por su propio análisis, en efecto, podemos tirar y acompañar al tipo antropológico cínico de la nueva sociedad capitalista, un segundo tipo antropológico capaz de mantener el sistema y de reproducirlo: el esclavo feliz, distraído, estúpido y divertido. No solamente manipulado, sino totalmente integrado dentro del sistema general de la manipulación, que este tipo de individuo reclama y defiende. No solamente obediente, sino que defiende el sistema de la injusticia y la dominación que lo impulsa constantemente a un estado de minoría de edad. Alguien que lucha para quedarse ahí, y contra su autonomía.

La tendencia totalitaria se impone por que la victoria del capitalismo se nutre no solamente del conformismo generalizado, sino también de la emergencia de una forma de organización nihilista de sentido colectivo y del suicidio de la valorización del social-histórico. Esta nueva sociedad es ante todo una nueva organización de la sociedad, y la descomposición no es un fenómeno que toca a la sociedad en tanto tal. La suspensión de la inversión en la importancia del sentido y su profunda dimensión efímera no eliminan la búsqueda necesaria de inversiones positivas y durables que caracteriza todavía la sociedad capitalista, como cualquier otra sociedad.

En resumen, la insignificancia difundida debería ser relativizada y comprendida como un aspecto particular de una nueva y paradojal creación social-histórica, es decir ontológica, no como la forma de la sociedad o la dimensión central de su descomposición. Solamente dentro de este cuadro se establece una nueva sociedad caracterizada por una heteronomía débil, donde, sin embargo, la época precedente, con su componente de autonomía, no está muerta.

\section{El proyecto de autonomía hoy}

Castoriadis se muestra algo inseguro sobre la perspectiva del proyecto de autonomía: él pregunta a menudo sobre su desvanecimiento, se pregunta si su debilidad es el signo de un período histórico particular o de una disolución del 


\section{PROIFIETEICA}

conjunto de la historia occidental, o todavía de la insuficiencia por la que se presenta hoy (bajo las caras del liberalismo y del marxismo). La disolución de la valorización de lo Social-histórico, la insignificancia devenida modus vivendi, el conformismo difundido dentro de un nuevo sistema de dominación y la ausencia de un movimiento revolucionario, conducen a nuestro filósofo a un profundo escepticismo, en parte justificado. Esta sociedad, en efecto, parece organizarse como un rechazo de sí misma, en la medida en que rechaza la vida social y la historicidad fuerte en tanto tales. Gracias al imaginario capitalista encarnado en las instituciones de la privatización y de la burocratización generalizada ella es alimentada en exceso por la corrupción sistemática, medio privilegiado para el enriquecimiento y la acumulación del capital.

Sin embargo, pese a todo esto, este imaginario no ha logrado eliminar el proyecto de autonomía, como lo hemos visto en particular en los últimos quince años. Y es por ello que a fin de comprender el estado del este proyecto hoy, sería bueno volver de manera dialéctica a la reflexión sobre la doble realidad de la época actual: de un lado, sobre la afirmación de una nueva forma de servidumbre voluntaria y la dominación que exige y, por el otro, sobre las nuevas instancias del proyecto de autonomía todavía en vida.

\section{Sobre la nueva servidumbre voluntaria}

Cuando La Boétie ha hablado por primera vez de la servidumbre voluntaria, se ha referido a una forma de habito devenido una segunda naturaleza, una suerte de perversión por relación a la propensión natural a la libertad, una aversión radical a la amistad, y la emergencia de una costumbre marcada por la crueldad, la injusticia y la deslealtad (La Boétie, 1983: 145/150/168). Varios años más tarde, Simon Weil ha subrayado que este hábito tiene la necesidad de que la mentira y la impotencia se enraícen y se difundan en el conjunto del tejido social en lugar de la capacidad de pensar y amar (Weil, 2002: 118-9). Es curioso que, en el debate desarrollado en el curso de estas últimas décadas sobre la servidumbre voluntaria (Zarka, 2007) ${ }^{52}$, hemos puesto luz sobre todo a la

52. Ver por ejemplo: Lorenzo Passarini, Natura umana e propensione al servilismo politico in Étienne La Boétie (http://www.montesquieu.it/biblioteca/Testi/Saggio bo\%C3\%Agtie.pdf). 


\section{PROIFIETEICA}

corrupción moral y al interés mezquino para la homologación social actual, o incluso la renuncia a la capacidad y a la posibilidad de elegir, más que a un diagnóstico que esté en condiciones de indicar un antídoto hipotético contra esta forma de veneno para la autonomía humana.

Aunque no se refiere explícitamente a la tesis de La Boétie, el primero que ha dado un diagnóstico de este tipo con una cierta profundidad intelectual ha sido Erich Fromm. Trasladando el problema de la servidumbre voluntaria al centro del análisis de las raíces de la sociedad totalitaria, el propone su famosa tesis sobre la huida de la libertad para aclarar, de hecho, la estructura social del capitalismo monopólico: el nuevo rostro de la civilización industrial transforma al individuo en un autómata aislado y desprovisto de un Yo capaz de asumir la responsabilidad y de darse sus propias finalidades, así como el sentido de la existencia y de su propia identidad, a fin de comprender qué es lo que quiere de la vida, y de actuar espontáneamente y libremente. Según Fromm, la impotencia, generada por la reducción del individuo en autómata, está vinculada a la penalización social de la espontaneidad y del espíritu crítico, y por el temor de ser desaprobado y de ser progresivamente aislado de sus prójimos, que, a su vuelta, esconde su terror de poder perder su salud mental y todo lo que queda de su identidad. La servidumbre voluntaria a la base de la sociedad contemporánea que ha nutrido al totalitarismo, en substancia, es el producto de un conformismo obsesivo que se nutre, por un lado, de autoritarismo político y económico, y por el otro, de una reducción de la capacidad de autodeterminación del individuo (Fromm, 1978: 112-14/127/136/1634/170/210/216-24/231-2).

Un análisis similar ha sido formulado recientemente, bajo la forma de sospecha, por el filósofo italiano Alfonso M. Iacono, pero, en su caso, él ha relacionado a la sociedad democrática que ha salido victoriosa de la confrontación con el totalitarismo, incluso si ha sido presa de libertades organizadas de manera oligárquica. Desde su punto de vista, la huida de la libertad corresponde a la formación de un proceso de naturalización de la existencia sostenido por un profundo deseo de quedar en estado de minoría de 


\section{PROIFIETEICA}

edad: el estado producido por la dominación tranquiliza y respeta todo lo que es familiar, o pertenece a la rutina y la seguridad, poniendo en marcha un proceso de banalización de la existencia que no es más que una dinámica dentro de la que el poder se legitima para sí mismo y se preserva en detrimento de la posibilidad de crear una distancia con el presente y el status quo - posibilidad que está a la base de la autonomía humana. Según su perspectiva, hay procesos en curso según los cuales preferimos la alegría de quedar en el estado de minoría de edad y la liberación de la carga de la autonomía antes que sobrellevar el miedo y salir del estado de seguridad para aceptar y afrontar la contingencia de la vida. Desarrollar la capacidad de ver con ojos diferentes, es decir, entrar en la dimensión del homo dúplex capaz de tomar las distancias críticas sabiendo reconocer los aspectos de la realidad, o sea nuestros límites, es, según Iacono, el principal antídoto a esta deriva heterónoma (Iacono, 2000: 26/40/86-89/96/119/139/158/162/164).

Hace algunos años el filósofo del derecho Fabio Ciaramelli ha planteado el problema de la servidumbre voluntaria actual señalando que es posible vincular la referencia a la sociedad totalitaria con el problema actual del deseo de permanecer dentro de la minoría de edad, que caracteriza las democracias liberales. La obediencia a las configuraciones predeterminadas de comportamiento que levantan la carga de decisión y de la elección, siguiendo un orden tranquilizador que conduce, al mismo tiempo, al sacrificio de la autodeterminación individual, marca profundamente nuestras sociedades, distinguidas por el divorcio entre el capitalismo y la democracia. Según Ciaramelli las causas de la perdida de libertad y el hecho de que dejamos de considerarla como deseable, están ligados a una patología del deseo que conduce a una denegación activa de la libertad y de la vida. El deseo deviene una satisfacción solitaria y garantizada, porque no depende más del acuerdo con los otros, mientras que la obediencia se transforma en sumisión disciplinaria, para destruir la naturaleza riesgosa e incierta de las relaciones humanas y de este modo generar una libertad paradojal y autodestructiva que evite al deseo el agotador pasaje por la mediación social. Satisfacción solitaria y sumisión disciplinaria impiden que asumamos realmente la libertad. El deseo de libertad, 


\section{PROIFIETEICA}

en particular, está vinculado a la incapacidad de construir su propia identidad, y por esta razón se transforma en su contrario, es decir, en servidumbre voluntaria (Ciaramelli, 2013: 6o/73-4/79-80/103-10/113).

Cada pensador, entre los considerados, recupera aspectos importantes y necesarios para la comprensión del fenómeno en cuestión, y también la paradoja y la contradicción de un mundo que utiliza la libertad contra ella misma. Ninguno entre ellos, sin embargo, discierne lo que ha enraizado en la profunda necesidad del conformismo: no solamente en el miedo, en el deseo de seguridad, en la necesidad de ser aceptado por la comunidad o de comprender su propia identidad en relación con ésta, sino sobre todo en el respeto de las reglas (explícitas o implícitas), es decir, en el carácter decisivo de la institución de la realidad. De la regla en tanto que necesidad psicosocial de la socialización.

En todas estas importantes tesis, de las que he expuesto lo esencial, lo que no ha sido suficientemente tomado en cuenta es la naturaleza institucional del conformismo, a saber, la necesidad de respetar las reglas de conducta independientemente de la construcción de la identidad, del deseo de libertad, o de la toma de consciencia del estado de sumisión a la minoría de edad al que estamos adaptados. La potencia del conformismo actual se oculta mostrando la importancia que la socialización juega dentro de la formación del consentimiento y dentro de la aceptación del status quo, de manera que haya la sospecha de que el problema de la servidumbre voluntaria no debe ser buscado dentro del cuadro de la libertad que produciría su contrario- sino de hecho de que su ejercicio imposible se ha vuelto una norma central en el marco de la reproducción social. Por consiguiente, sería importante estudiar la naturaleza de la organización del poder capitalista actual, es decir, no solamente la estructura de dominio que obtiene el consentimiento de la población, sino las formas de socialización dentro de las que se reproduce continuamente el ejercicio del poder en tanto que favor, privilegio, delegación, aceptación de la corrupción de las reglas establecidas, de la incapacidad de valorar la norma común, como las normas centrales de la coexistencia. Cuando la regla no está justificada más que sobre la base de la autoridad que restaura el orden en la relación con el prójimo, de la significación y del mando, mientras que toda 


\section{PROIFIETEICA}

norma de libertad es abolida y el principio de autoridad impone reglas exteriores a los sujetos. Como cuando el conflicto no es más que la expresión de la violencia y de la aniquilación. En definitiva, todo lo que aleja la libertad de del individuo, de origen moderno, de la libertad con, ligada al amor, a la amistad y a la autonomía, a las que se refieren Fromm, La Boétie y Iacono, que parece residir principalmente en la manera en que se instituyen las reglas de coexistencia, y por lo tanto, en la naturaleza de poder compartido.

\section{La transformación del proyecto de autonomía}

Más allá del socialismo y el comunismo, pero también del Mayo del '68 y de los movimientos que están ligados, hay también otros momentos de la historia del siglo pasado donde podemos encontrar nuevas y originales modalidades en las que el proyecto de autonomía se ha mostrado presente.

En primer lugar en Brasil, donde un movimiento popular, constituido por una pluralidad de movimientos de reivindicación de una nueva sociedad y de una verdadera democracia, ha logrado entrar en la vida pública y política y movilizar una parte importante de una sociedad en la que el poder político y la dictadura militar expresaban claramente las características de una dominación nutriéndose de una conformidad servil y de la aceptación del principio de autoridad. La progresiva y larga descomposición del régimen militar ha sido directamente proporcional a la emergencia de una nueva concepción y práctica de poder político y popular, hasta conducir a una verdadera tentativa de creación política. (Profumi, 2013: 115-226) Aunque limitado y, a fin de cuentas, sin éxito, el caso de Brasil contemporáneo permite comprender que la existencia del proyecto de autonomía ha tomado formas aparentemente menos intensas que las del movimiento socialista o comunista, pero siempre pertinentes para la comprensión de las posibilidades de creación política y de la realización de la autonomía humana.

Después de la muerte de Castoriadis, el proyecto de autonomía, que él ha visto emerger por última vez en las revueltas del Mayo del 68', vuelven con el movimiento altermundista, a fines de los años 1990, y con el movimiento de los 


\section{PROIFIETEICA}

indignados, después del 2007. Contra el nuevo curso del capitalismo financiero mundial, el movimiento de movimientos llega a hacer esto que Castoriadis, después de 1968, había reprochado no haber realizado a los movimiento sociales (en particular al ecologista y al de las mujeres) (Castoriadis, 1996: 17): construir un frente único, formado en este caso, por todos aquellos que, a partir de diferentes posiciones y con diferentes perspectivas, luchan por el fin del sistema neoliberal y por la afirmación de otra sociedad global posible, antitética a la capitalista. A lo largo del mismo camino, que se ha desplegado solamente hace diez años, el movimiento de los indignados ha compartido y vuelto populares numerosas posiciones, ideas y proposiciones altermundistas, guardando siempre la misma aversión por la dominación económica y política infringida por los defensores del orden capitalista.

Los dos movimientos están todavía activos. El movimiento altermundista en 2015 celebra su onceavo Foro Social Mundial en Túnez, mientras que el movimiento de los indignados, que se compone principalmente de grandes manifestaciones populares y de la activación de un sistema de asambleas públicas donde organizar una nueva vida democrática partiendo de la base, hoy se presenta bajo su nueva forma de mareas y de la lucha por la democratización de los servicios sociales (pero también, en parte, bajo la forma del partido Podemos). Hablamos de un cierto número de asambleas barriales o de pueblo, de colectivos, de asociaciones, de cooperativas y de otras realidades colectivas auto-organizadas que se han propagado y han creado redes, coordinando su acción con los problemas más urgentes que resienten a la población menos integrada en el sistema actual (la casa, la salud, etc.). El proceso de reinvención de la imaginación política que ha comenzado con el movimiento altermundista a nivel planetario, se persigue, a nivel local, por el movimiento de los indignados. La referencia a las formas antiguas y nuevas de autogestión y de democracia directa, la utilización de internet y de las dinámicas horizontales, necesarias para organizarse y comunicarse, es la nueva cara de proyecto de autonomía: no estamos en presencia de un desvanecimiento de este proyecto sino de su novedad planetaria, ya que toma en adelante nuevas formas de organización y un nuevo imaginario. Estos movimientos actuales han aprendido a menudo de 


\section{PROIFIETEICA}

las lecciones de los errores de los movimientos de 1900, pero tienen reparos al abandonar completamente la heteronomía social contra la que luchan. Los dos son, de hecho, los vehículos de las cuatro condiciones que se muestran necesarias para la creación política: la politización progresiva de la sociedad, la expresión de una sociedad diferente, la demanda de una verdadera democracia, y la práctica no-violenta de los conflictos sociales y políticos.

Sin embargo, el proyecto de autonomía no puede ser alcanzado solamente gracias a estos dos movimientos. El primero se auto-representa como un largo proceso de transformación de las instituciones mundiales, y por esta razón ha formulado objetivos que puedan abrir la posibilidad de una real transformación de estas instituciones, así como un refuerzo de todos los movimientos populares, sociales, civiles, que luchan contra el sistema capitalista. El segundo es, ante todo, un movimiento de protesta y de deslegitimación de las instituciones económicas y políticas oligárquicas, pero también de creación de un nuevo imaginario democrático. Las dos son condiciones esenciales para todas las formaciones revolucionarias que se orientan a la creación política, pero no constituyen, en tanto tales, el agente de un nuevo tipo de revolución.

\section{4. "Crisis y polarización"}

Frente a esta doble tendencia general, es importante que recordemos esto que el filósofo francés Daniel Bensaïd escribió de sus últimas obras sobre la sociedad contemporánea: "la idea de una revolución tiende a perder su propia substancia política para ser reducida a una postura de deseo estético o ético, a un juicio de gusto, o a un acto de fe". (Bensaïd, 2007: 2) ${ }^{53}$. El hecho de que la revolución no sea una tabula rasa, sino que ella tenga las condiciones sociales-históricas y que ella deba ser una reorganización de las relaciones sociales y una revisión de la temporalidad, no significa que podamos predecirla o que no sea intempestiva, como lo ha recordado Bensaïd (Bensaïd, 2007: 4). Acontecimiento e historia, salto y proceso, creación y construcción, no son una antítesis ni están en oposición, como ha sido indicado por los que escinden el momento del tiempo

53http://danielbensaid.org/Desir-ou-besoin-de-revolution?lang=fr 


\section{PROIFIETEICA}

instituyente del tejido instituido y piensan que la creación política es un milagro o un momento de suspensión del orden impuesto (Badiou, 1988), pero también por los que piensan la novedad como fuertemente condicionada por los presupuestos históricos (Dardot y Laval, 2014). Al final de su vida, Castoriadis ha imaginado el advenimiento de una bifurcación histórica, entre la dominación del imaginario capitalista y el deseable e impredecible despertar social y político del imaginario creador (Castoriadis, 1999: 109-10). Él no ha visto que esta bifurcación estuviera en tren de producirse o devenir más radical de lo que había percibido.

Habida cuenta de la polarización actual de la sociedad a la heteronomía débil, es decir, de cara al resurgimiento de la lucha social y política contra el sistema capitalista, aunque débil y contradictoria, pero también delante de la radicalización del ataque a esto que queda de la herencia del proyecto de autonomía sedimentado dentro de nuestras sociedades occidentales, vivimos una vez más dentro de una situación de crisis en el sentido etimológico del término Krisis. Esto que Bensaïd recuerda que es una situación dominada por una bifurcación y por la necesidad de elegir el momento donde se imponen verdades históricas más allá de la mentira del presente eterno que está a la base del nuevo curso del capitalismo globalizado y financiero. La crisis económica ha abierto la caja de Pandora de una crisis de la sociedad ya en acto. En despecho por ser utilizado como una herramienta ideológica para imponer sociedades completamente heterónomas- esto que había llegado también con la lucha contra el terrorismo - "la crisis" ha servido para despertar consciencias dormidas y expresar claramente la nueva alternativa a la que cada uno de nosotros tiene que responder: ¿democracia o capitalismo?

Para hacerlo será necesario comprender por qué, y en que medida, los aspectos de las sociedades totalitarias están reproduciendose y radicalizandose de una manera nueva en nuestras sociedades.

Una primera reflexión a la que es necesario tener en cuenta es la del psiquiatra y psicoanalista Christophe Dejours, que recupera de un modo particularmente cristalino la manera en que la servidumbre voluntaria echa raíces en el sistema neoliberal y produce formas de aceptación parecidas a esto 


\section{PROIFIETEICA}

que Hannah Arendt llamaba la banalidad del mal refiriéndose al sistema nazi. Dejours orienta su atención analítica hacia el establecimiento de las reglas de organización neoliberal de las empresas, y pone a la luz que los principios de organización que ahí se imponen son la falta de moral, la mentira sistemática, la injusticia, el sufrimiento continuo e ignorado, y la tolerancia o aceptación general de estos principios. Del mismo modo que el régimen nazi había logrado hacer pasar el mal por el bien, igualmente en el sistema neoliberal la maldad del comportamiento, que antes constituía un caso excepcional, deviene un valor normal de comportamiento. El miedo y las mentiras sistemáticas permiten una banalización de la violencia, y la formación de grupos de colaboradores capaces de tirar dentro del sistema a las personas que están implicadas ahí pero que mantienen todavía una moral intacta. Como para Arendt, para Dejour el problema más grande es que la responsabilidad de la mayoría de la gente es central y directa en el proceso de una aceptación resignada y en la celosa reproducción de un sistema que recompensa la anulación de la capacidad de razonamiento y de empatía frente al sufrimiento del otro. La banalidad del mal no nace como una patología psicológica, sino como normalidad, por siniestra y perversa que sea. (Dejours, 2009: 75/77/90/100/105-8/113/117/1412/157/164/179/182-3/191-2/194/202-3/219).

Sin embargo, contrariamente a esto que es indicado por Dejours, la reducción o eliminación de la consciencia, debida a la valoración de las normas violentas y contrarias a la autonomía humana, no se produce solamente en el mundo del trabajo, y la supresión de la facutlad de pensar no se reduce a la falta de comprención del malestar de los otros, sino que ella es en lo sucesivo una parte improtante de las costumbres y de la cultura de nuestra sociedad. La pobresa humana, la exclusión y la violencia generadas por el éxito de formas econonómicas que han progresado gracias a la corrupción y al cinismo, y que han sido aceptadas y sostenidas por las "reglas" del mercado, a saber, por el imperativo del beneficio a todo precio, no son más que la punta del iceberg de un sistema social que se muestra listo para el advenimiento de una nueva forma de heteronomía, mucho más dura de la que nos habla Castoriadis.

El proyecto de autonomía depende sobre todo de una incertidumbre: ćlos 


\section{PROIFIETEICA}

movimientos sociales internacionales lograrán prolongar la crisis y llevar partes más grandes de la población a elegir sus perspectivas? ¿Vamos a imponer, una vez más, la elección entre la servidumbre y la autonomía en el curso de nuestra historia? Y, en última instancia ¿Lograremos poner la creación política en el corazón de nuestra perspectiva revolucionaria?

\section{Bibliografía}

BADIOU Alain (1988). L'Être et l'événement, Paris: Seuil.

BENSAÏD Daniel (publication inconnue, probablement 2007). Désir ou besoin de révolution?

CASTORIADIS Cornelius. (1990). L'époque du conformisme généralisé, en C. Castoriadis, Le monde morcelé, Paris: Seuil. [En español: El mundo fragmentado, La Plata, Terramar. 2008)

----------. (1996). La montée de l'insignifiance y La crise du processus identificatoire y La crise des sociétés occidentales, en C. Castoriadis, La montée de l'insignifiance, Paris: Seuil. [En español: C. Castoriadis, El avance de la insignificancia, Eudeba, Bs. As., 1996.]

----------. (1999). Imagination et imaginaire au carrefour y Héritage et révolution y Quelle démocratie? en C. Castoriadis, Figures du Pensable, Paris: Seuil. [En español: Figuras de lo pensable, Bs. As., Fondo de Cultura Económica, 2006]

- (2011). Ni nécessité historique, ni exigence seulement « morale »: une exigence politique et humaine y Une société à la dérive, en C. Castoriadis, Une société à la dérive, Paris: Seuil. [En español: Una sociedad a la deriva. Entrevistas y debates (1974-1997), Bs. As., Katz, 2006]

(2013). Spécificité et crise des sociétés occidentales, en C. Castoriadis, Quelle démocratie ? Tome 2. Ecrits politiques 1945-1997, IV, Paris: Sandre. CIARAMELLI Fabio (2013). Dal consenso alla legittimazione. Le vicissitudini della servitù volontaria ieri e oggi, en Fabio Ciaramelli y Ugo Maria Olivieri, Il fascino dell'obbedienza. Servitù volontaria e società depressa, Milano-Udine: Mimesis. 


\section{PROIDIETEICA}

DARDOT Pierre y LAVAL Christian (2014). Commun. Essai sur la révolution au XXIe siècle, Paris: La Découverte.

DEJOURS Christophe (2009). Souffrance en France. La banalisation de l'injustice sociale, Paris: Seuil.

FROMM Erich (1978). Fuga dalla libertà, Milano: Edizioni di Comunità.

IACONO Alfonso M.aurizio (2000). Autonomia, potere, minorità. Del sospetto, della paura, della meraviglia, del guardare con altri occhi, Milano: Feltrinelli. LA BOÉTIE Étienne (1983). Discours de la servitude volontaire, Paris: Flammarion.

PROFUMI Emanuele (2013). Sulla creazione politica. Critica filosofica e rivoluzione, Roma: Editori Riuniti Internazionali.

WEIL Simone (2002). Méditation sur l'obéissance et la liberté, en Étienne La Boétie, Discours de la servitude volontaire, Paris: Petite Bibliothèque Payot.

ZARKA Yves Charles et Les Intempestifs (2007). Critique des nouvelles servitudes, Paris: Puf. 